Estudios Constitucionales, Año 12, No 1, 2014, pp. 475-500.

ISSN 07180195

Centro de Estudios Constitucionales de Chile Universidad de Talca

"Reformas de la ejecución civil y del proceso monitorio: la apuesta chilena por la tutela judicial efectiva y el derecho de acceso a un debido proceso"

Diego Palomo Vélez

\title{
REFORMAS DE LA EJECUCIÓN CIVIL Y DEL PROCESO MONITORIO: LA APUESTA CHILENA POR LA TUTELA JUDICIAL EFECTIVA Y EL DERECHO DE ACCESO A UN DEBIDO PROCESO*
}

\author{
AMENDMENTS OF THE CIVIL ENFORCEMENT AND THE SMALL CLAIM \\ PROCEEDINGS: CHILE BETS ON AN EFFECTIVE JUDICIAL PROTECTION AND ON \\ THE RIGHT TO LEGAL REPRESENTATION IN A DUE PROCESS
}

\author{
Diego Palomo Vélez** \\ Universidad de Talca - Chile \\ dpalomo@utalca.cl
}

RESUMEN: Este trabajo es el informe nacional de Chile elaborado para las XXIV Jornadas Iberoamericanas de Derecho Procesal, realizadas en Ciudad de Panamá, entre el 26 y el 28 de marzo de 2014, sobre la situación de las reformas del proceso de ejecución civil y del proceso monitorio en el pais. La idea fundamental que está detrás es la cuestión de la buisqueda de la eficiencia en la Justicia en un contexto dónde se reclama contra la lentitud con la que los tribunales brindan respuesta a los justiciables, sin afectar el derecho al debido proceso.

ABSTRACT: This work is the Chilean national report about the situation of the amendments in the civil enforcement proceeding and in the small claim proceeding. The main idea that supports it, is the search of justice efficiency without affecting the right to a due process, all these, in a context where everybody complains about court slowness to provide a proper answer to the justiciable. This work was

\footnotetext{
* Este trabajo se realiza dentro del marco del proyecto Fondecyt regular: "Estudio crítico del nuevo proceso laboral chileno a la luz de las exigencias del derecho al debido proceso" (No 1120409), y constituye el informe nacional de Chile para las XXIV Jornadas Iberoamericanas de Derecho Procesal, realizadas en Ciudad de Panamá, entre el 26 y el 28 de marzo de 2014.

** Profesor de Derecho Procesal en la Facultad de Ciencias Jurídicas y Sociales de la Universidad de Talca. Doctor en Derecho por la Universidad Complutense de Madrid. Director del Departamento de Derecho Penal, Procesal y Trabajo, ex Director de la Revista Ius et Praxis. El autor agradece especialmente los aportes y complementos del colega y amigo Dr. Jordi Delgado Castro, también profesor de Derecho Procesal de la Facultad de Ciencias Jurídicas y Sociales de la Universidad de Talca, Doctor en Derecho por la Universidad de Barcelona, a cuyo cargo se encuentra la dirección y ejecución de un recientemente adjudicado proyecto Fondecyt de iniciación: "Problemas de diseño del procedimiento monitorio civil chileno. Una evaluación desde las experiencias del Derecho Comparado". Además el autor quiere agradecer la colaboración de sus ayudantes D. Williams Valenzuela, abogado de la Universidad de Talca, y D. Diego Valdés Quinteros, estudiante de la carrera de Derecho en la Universidad de Talca.
} 
made for the XXIV Jornadas Iberoamericanas of Procedural Law, in Ciudad de Panama, which were carried out from march $26^{\text {th }}$ to march $28^{\text {th }}, 2014$.

PALABRAS ClaVE: Ejecución civil, Procedimiento monitorio, Eficiencia judicial, Debido proceso.

KEY WORDS: Civil enforcement, Small claim proceeding, Judicial efficiency, Due process.

\section{INTRODUCCIÓN}

He recibido de parte del Prof. Dr. Joan Picó i Junoy el encargo de responder como informante nacional de Chile una serie de preguntas relativas a la situación de las reformas del proceso de ejecución civil y del proceso monitorio en mi país ${ }^{1}$. Antes de proceder a contestarlas, estimo conveniente y hasta necesario contextualizar este informe nacional en el marco del proceso de reformas procesales que el país viene experimentando desde hace un tiempo. En efecto, en los últimos años el sistema chileno ha puesto en vigor una serie de reformas que han conseguido cambiarle el rostro a una Justicia que progresiva y peligrosamente, con el paso de los años y la perpetuación de un modelo ya agotado, estaba perdiendo cuotas de confianza en la ciudadanía. Esta desconfianza de los ciudadanos en la actuación de los tribunales de justicia, cuestión fundamental para la estabilidad de todo Estado de Derecho, y la impostergable necesidad de poner al día nuestro modelo de Justicia a la luz de los avances mejor probados del Derecho comparado, impuso la necesidad de introducir reformas generales que fuesen más allá de las modificaciones parciales a las que nos tenía acostumbrados el legislador.

Las reformas que para los efectos de este reporte nos importan fueron pensadas y diseñadas a fines del siglo pasado, comenzando por el sistema jurisdiccional penal, donde Chile se anotaba un sistema ampliamente criticado por su naturaleza eminentemente inquisitiva, su deficitaria compatibilidad con los postulados elementales del derecho al debido proceso, sin pasar por alto su escasa eficiencia ${ }^{2}$.

Haber logrado cambiar este modelo inquisitivo por uno adversarial, haber asumido un sistema respetuoso de los postulados elementales del debido proceso y cuidadoso de una persecución penal eficiente a través de la creación de un órgano especializado como lo es el Ministerio Público, y haber incorporado diversos instrumentos de selectividad penal y mecanismos alternativos de resolución de conflictos significó no sólo lograr un mejoramiento sustantivo en los estándares de derechos y garantías de las personas, sino situarse en el selecto grupo de sistemas que sirve de referencia a otros procesos de reforma en la Región y fuera de ella. Se trató de una ambiciosa reforma

${ }^{1} \mathrm{Al}$ inicio de los siguientes capítulos de este informe, como nota al pie, se recogen las preguntas.

${ }^{2}$ Leyes Nos. 19.696, 19.640 (LOC del Ministerio Público) y 19.718 (Crea la Defensoría Penal Pública). 
total del modelo procesal hasta ese momento vigente, buscando una Justicia imparcial, oportuna y transparente, sobre la base del reemplazo del predominio absoluto de la escrituración por la instalación del mecanismo del juicio oral ${ }^{3}$.

El proceso de cambios no se ha detenido en la reforma procesal penal. En efecto, tras la citada reforma se han puesto en marcha los cambios en otros órdenes jurisdiccionales, como lo son la Justicia de familia ${ }^{4}$ y la Justicia laboral ${ }^{5}$, que desde el punto de vista de los objetivos han mostrado un explícito compromiso con una mejora en la eficiencia del desempeño de la Justicia también tratándose de esa clase de controversias.

En ambas reformas, la decisión procesal central estuvo dada por la asunción de un proceso por audiencias, al cual se le reconoció una serie de ventajas por sobre lo que ofrecía el modelo escriturado, en especial desde la perspectiva del acceso de los ciudadanos a la Justicia y la obtención de mayores grados de eficiencia, incluyendo el acortamiento del horizonte temporal que el justiciable debe proyectar desde la iniciación del juicio respectivo hasta que la decisión se hace ejecutable. Lamentablemente, decisiones a nuestro juicio equivocadas, como pretender que la obligatoriedad de la comparecencia en juicio mediante abogados era innecesaria, desequilibrar excesivamente la distribución de roles de jueces y abogados, y errores de cálculo a la hora de acompañar la reforma procesal de los recursos humanos y materiales suficientes para llevar adelante un cambio de esta naturaleza y envergadura, terminaron afectando, en cierta medida, el resultado efectivo obtenido. Si bien se han realizado ajustes y correcciones a los sistemas reformados, tanto en su dimensión procedimental como orgánica, sobreviven algunos problemas de los que está pendiente hacerse cargo ${ }^{6}$.

\footnotetext{
3 Sin perjuicio, por cierto, de las reformas parciales que se le han introducido al Código Procesal Penal en los años de vigencia que acumula. Entre ellas: Ley No 20.592, Ministerio del Interior y Seguridad Pública; Subsecretaría del Interior, derecho de defensa a los imputados; Ley No 20.253; Ministerio de Justicia, modifica el Código Penal y el Código Procesal Penal en materia de seguridad ciudadana, y refuerza las atribuciones preventivas de las policías (conocida como la Ley de Agenda Corta); Ley No 20.074, Ministerio de Justicia modifica los Códigos Procesal Penal y Penal; Ley No 19.942, Ministerio de Justicia, modifica los Códigos de Procedimiento Penal y Procesal Penal en materia de control de identidad; y la Ley No 19.789, Ministerio de Justicia introduce modificaciones al Código Procesal Penal.

${ }^{4}$ Leyes $\mathrm{N}^{\circ}$ s. 19.968 y 20.286.

5 Leyes Nos. 20.087, 20.260 y 20.287.

${ }^{6}$ Con el paso del tiempo ha perdido intensidad en el país la conciencia de que en un proceso de reformas general que aspira a ser exitoso juegan un rol una multiplicidad de factores que están concatenados. No basta con un buen diseño procesal.
} 
Como sea, con independencia de cuáles han sido los resultados concretos de cada una de las reformas implementadas, todas han asumido como idea central para la mejora del funcionamiento de la Justicia la conveniencia y hasta la necesidad de adoptar la oralidad como forma protagonista en el nuevo sistema, la que se instaló entre nosotros como la mejor fórmula para enfrentar los males que aquejaban a la Justicia, principalmente su ineficiencia y lentitud en la respuesta jurisdiccional que se estimaba, con razón, un atentado a la tutela judicial efectiva ${ }^{7}$.

Es en este contexto y con estos precedentes que se asume el desafío de trabajar en una reforma a la Justicia civil, que muestra al día de hoy un escenario afectado por una grave obsolescencia (con un Código vigente desde 1903, que sigue el modelo de las LEC españolas del siglo XIX), situación especialmente preocupante si se considera que estamos haciendo la referencia al sistema procesal general $y$ supletorio de todos los demás.

Tras no pocos años de discusión, debate y un Proyecto frustrado, en marzo del presente año, bajo el gobierno del Presidente Piñera, se ingresa a tramitación ante el Congreso Nacional un Proyecto de nuevo CPC (Mensaje No 432-359, 12 de marzo de 2012) ${ }^{8}$. En efecto, el trabajo se remonta al año 2005, en la cual comienza a trabajar el Foro Procesal Civil sentando las bases generales y principios del nuevo sistema. Realizado ese trabajo, el Ministerio de Justicia de la época encarga a la Facultad de Derecho de la Universidad de Chile la redacción de un Anteproyecto de CPC, basándose en el trabajo efectuado. Cabe señalar de inmediato que desde un comienzo existió el consenso respecto a que no bastaba con concordar parches para la normativa vigente, siendo perentorio realizar una reforma sistemática e integral, adoptando los principios y modelos que la doctrina había venido postulando desde hace más de un siglo. Pues bien, el Anteproyecto sirvió para que el Foro trabajara pormenorizadamente en un texto que se transformaría en el Proyecto de nuevo CPC, ingresado al Congreso en el mes de mayo del año 2009, bajo el gobierno de la ex Presidenta Bachelet.

Al asumir el Presidente Piñera el año 2010, decide tomar la reforma como uno de los objetivos de su gobierno, para lo cual instruye dedicarse prioritariamente a la revisión del proyecto ingresado, encargando su adecuación a los principios que inspiran su gobierno. Para ello el ministro de Justicia de la época trabajó, durante casi un año y medio, en reuniones semanales, con una Comisión Intraministerial integrada por tres

\footnotetext{
7 Respecto a la oralidad en Chile y otros temas conexos, véase especialmente: PALOMO (2010).

${ }^{8}$ Su texto se puede revisar fácilmente en http://rpc.minjusticia.gob.cl/media/2013/04/Proyecto-de-Ley-deNuevo-Codigo-Procesal-Civil.pdf Consultado con fecha 9/11/2013.
} 
profesores de Derecho Procesal, la que revisó, perfeccionó y brindó mayor coherencia al Proyecto de 2009. El producto de este trabajo luego fue revisado y complementado, en sucesivas entregas, por un Consejo Asesor de la Reforma, integrado por seleccionados académicos y representantes del foro, perfeccionándose y quedando en condiciones de ser ingresado -como otro Proyecto- para su tramitación en el Congreso Nacional.

Trátase, nuevamente, de un Proyecto de nueva regulación procesal civil que, junto con tomar partido por la fórmula de la oralidad, apuesta por la búsqueda de la eficiencia y por una concepción de proceso en dónde, además del interés privado que se asume lo integra, existe un interés público, comprometido en una resolución rápida, eficaz, justa y fundada en derecho del conflicto 9 . Desde el modelo de proceso por audiencias, la oralidad y sus bien difundidas reglas conexas se persigue dar vuelta la página no sólo respecto de una de las características que más ha marcado el deficiente desempeño del actual sistema de Justicia civil, la escrituración, sino también respecto a la incidencia del factor tiempo en la respuesta jurisdiccional.

Es este escenario procesal, que no privilegia la eficiencia del sistema, el que se pone a disposición de los ciudadanos en el orden jurisdiccional civil. Como lo hemos dicho en otros sitios, la estructura escrita del proceso se ha convertido en la verdadera piedra de tope a las posibilidades de mejora de la Justicia, haciendo fracasar todo intento de cambio parcial. Resultaba impostergable ocuparse de la eficiencia, extraviada en sede civil, al hilo de lo que se ha venido planteando desde la doctrina procesal moderna y teniendo como referencia lo que otros países ya han realizado.

Tradicionalmente la cuestión de la buisqueda de la eficiencia en la Justicia ha sido ligada con la mejora en los tiempos de duración de los procesos que, con el sistema escriturado vigente casi monopólicamente hasta hace poco, no cumplen con un estándar razonable, reflejándose claramente en la lentitud con la que los tribunales brindan respuesta a los justiciables, debiendo pasar varios años para una respuesta jurisdiccional eficaz. El eslogan principal de esta última propuesta de reforma (al igual que ocurrió con las reformas a la Justicia de familia y laboral) ${ }^{10}$

\footnotetext{
${ }^{9}$ Proyecto de nuevo CPC, que en gran parte de su articulado se encuentra ya aprobado por la Comisión de Constitución, Legislación y Justicia de la Cámara de Diputados.

10 Así se ha destacado en otros informes: "Las reformas procesales y orgánicas al sistema jurídico chileno en los últimos 15 años como las actuales en curso tuvieron (tienen) como fin una justicia más rápida, eficiente, cercana a la gente, y transparente. Ello se plasma en la tutela adecuada de los intereses y derechos de los involucrados en cada uno de los conflictos. Las radicales reformas a la justicia penal, de familia y laboral son una evidencia de aquello. Pendiente ha quedado y está en curso la nueva justicia civil como la gran reforma”. VV.AA. (2012).
} 
ha estado, entonces, centrado muy fundamentalmente en hacerse cargo de la búsqueda de una mayor eficiencia desde la perspectiva del factor tiempo ${ }^{11}$, secuestrado por un modelo escriturado que se levanta desechando la concentración y que pone serias dificultades a la posibilidad de acortar el horizonte temporal de una respuesta jurisdiccional eficaz.

\section{REFORMAS DEL PROCESO DE EJECUCIÓN CIVIL ${ }^{12}$}

En la línea de lo que venimos señalando, una de las principales preocupaciones que el legislador ha tenido en Chile a propósito de la reforma a la Justicia civil ha sido la situación de la ejecución y es entendible que así sea desde el momento que la ejecución en tiempo razonable de las resoluciones judiciales (y títulos ejecutivos, agregamos nosotros) integra como elemento esencial, como bien se ha observado por la mejor doctrina, el derecho a la tutela judicial efectiva ${ }^{13}$ y el debido proceso ${ }^{14}$. Ya un estudio realizado por el Centro de Estudios de la Justicia (CEJA), analizando las causas civiles terminadas en el año 2009 en la capital del país Santiago, mostró alguna evidencia de lo que todos sospechamos, cual es el altísimo porcentaje de causas civiles que constituyen procedimientos ejecutivos. En efecto, el $96,45 \%$ de las causas civiles son procedimientos ejecutivos ${ }^{15}$ (porcentaje que se descompone, según este estudio, en un 70,55\% que comienzan con demanda ejecutiva y un $25,89 \%$ mediante gestión preparatoria de la vía ejecutiva),

\footnotetext{
11 En gran medida, a partir de la búsqueda de la celeridad, se ha impuesto entre nosotros una visión unidimensional o unidireccional de la eficiencia, descuidando muchas veces, por las prisas, la calidad de la Justicia. Es nuestro parecer que la búsqueda de una mayor eficiencia en la Justicia civil no debe agotarse en mejorar los índices o las estadísticas del factor tiempo, pues muchas veces la prisa puede esconder un deficitario desempeño en cuanto a otro de los aspectos que no debemos perder de vista jamás: la calidad del servicio justicia y del producto de la jurisdicción.

12 Reformas del proceso de ejecución civil.

1. Datos estadísticos

1.1. Si existen en el país (por favor, indicar la fuente de obtención de datos):

1.1.1. Nivel de eficacia de la ejecución civil (esto es, grado de satisfacción del crédito ejecutado)

1.1.2. Duración media de la ejecución civil

1.2. Si no existen: indica los posibles motivos de por qué no existen según tu experiencia

2. Principales motivos del fracaso/éxito de la ejecución civil

3. Indica las últimas medidas legislativas dirigidas a mejorar la ejecución civil y si han funcionado

4. Indica qué medidas crees que serían eficaces para mejorar la ejecución civil.

13 Píó (2012), pp. 93 y ss.

${ }^{14}$ De Hegedus; Romero (2010), p. 518.

15 Véase DucE et al. (2011), p. 16.
} 
constituyendo un factor derechamente clave en su influencia en la situación de una Justicia civil poco efectiva que termina acarreando el desprestigio del sistema. Otros documentos no coinciden exactamente en estos porcentajes, pero siguen advirtiendo del altísimo impacto que los procedimientos ejecutivos poseen en el funcionamiento de la Justicia nacional ${ }^{16}$.

El nivel de eficacia de la ejecución civil en Chile deja mucho que desear ${ }^{17}$. El grado de satisfacción del crédito ejecutado es verdaderamente preocupante. El mismo informe citado, y a la luz de las estadísticas que recoge, señala que sólo el $1,7 \%$ de los casos termina con una respuesta efectiva a la pretensión del actor, "ya sea mediante el pago de los créditos y/o la sentencia definitiva"18. Se debe agregar, para empeorar este escenario, que es muy alto el porcentaje de las causas que casi no tienen tramitación llegando a casi un $86 \%$, lo que pone de relieve otro tema que liga con malas prácticas por parte de los operadores del sistema, concretamente "un gran porcentaje de las demandas ejecutivas que se presentan a distribución no continúan con el proceso. Los ejecutantes utilizan la demanda, la que en varias ocasiones ni siquiera se notifica al ejecutado, sólo para amedrentar a sus deudores"19 (lo que se apoya en el escaso conocimiento de las personas respecto de las atribuciones de las empresas de cobranza o de los receptores judiciales), forzar negociaciones, o bien simplemente para "castigar la deuda" y de ese modo cumplir con las exigencias de la normativa del Servicio de Impuestos Internos respecto al tratamiento tributario del castigo de créditos in-

${ }^{16}$ Facultad de Derecho de la Universidad del Desarrollo (2013), p. 4. “...el ingreso judicial, en el ámbito civil, superó el año 2012, más de 2.100 .000 causas. De éstas, aproximadamente un $85 \%$ corresponde a juicios ejecutivos". Si se tiene presente que este dato sólo hace referencia a los juicios ejecutivos, el porcentaje real de incidencia llega fácilmente al 90\% aproximadamente si se consideran las gestiones preparatorias, porcentaje de incidencia que se viene manteniendo desde hace años. Véase en el mismo sentido, observando esta situación: VARGAS (2011), pp. 478 y 479; García; Leturia (2006), pp. 13 y 14.

${ }^{17}$ Algo sobre lo cual no existieron dos opiniones en las recientes II Jornadas Nacionales de Derecho Procesal, realizadas los días 7 y 8 de noviembre de 2013, bajo la organización del Instituto chileno de Derecho Procesal, donde uno de los cuatro paneles de trabajo estuvo destinado en exclusiva a la Ejecución.

18 DucE et al. (2011), p. 27.

19 "En el caso chileno, se ha identificado que una de las "raíces" centrales de la situación de sobrecarga y atochamiento de los tribunales civiles es la utilización de dichos tribunales no como un espacio jurisdiccional sino principalmente como una instancia burocrática que en gran medida realiza trámites que son: (i) meras formalidades para sólo iniciar sin dar prosecución a la ejecución; (ii) iniciar una ejecución que concluye por acuerdo de las partes; (iii) iniciar y proseguir la ejecución sin trabarse una contencioso por no haber oposición del ejecutado. De hecho, como se señala más adelante, el porcentaje de causas civiles que realmente son falladas por el juez no llega al 3\% de las causas ingresadas". VV.AA., Pontificia Universidad Católica de Valparaíso, op. cit., pp. 13 y 58. 
cobrables $^{20}$. También se ha destacado, desde la perspectiva del ejecutado, que del porcentaje total de procedimientos ejecutivos que si se tramitan sólo en un $17 \%$ se deducen excepciones, esto es, cuestionándose la validez, eficacia, exigibilidad o vigencia de la obligación ${ }^{21}$, no obstante se coincide en resaltar, desde otro punto de vista, que uno de los problemas del actual modelo y que ameritan un cambio sustancial, radica en el número y amplitud de los motivos de oposición que se le permite plantear al ejecutado, lo que no guarda relación con la necesidad de ejecutar una obligación que ya ha sido establecida fehacientemente ya sea en una sentencia firme o bien en un título ejecutivo, que en no pocas ocasiones tornan al procedimiento ejecutivo en un procedimiento de lato conocimiento ${ }^{22}$.

Las noticias que pueden darse sobre la duración de la ejecución civil dependen del tipo de término que tenga el procedimiento, que puede ir desde casos terminados por tenerse por no presentada la demanda, en los que no se da curso a la demanda o en las hipótesis de demandas sin movimiento, que en total llegan a sumar un $86 \%$ aproximadamente según un informe, a términos del procedimiento con pago del crédito y la sentencia definitiva que no alcanzan el $2 \%$ de las causas ejecutivas. En los primeros casos la duración promedio fluctúa entre los 45 y los 147 días. En las últimas hipótesis de término la situación varía radicalmente y los tiempos se desbordan fluctuando entre los 360 y los 472 días ${ }^{23}$. En otro informe las cifras varían levemente ${ }^{24}$.

20 Véase: http://www.sii.cl/documentos/circulares/2008/circu24.htm Consultado con fecha 6/11/2013. El impacto del crecimiento del sistema financiero también se ha relevado en otros informes. "Estamos inundados por el sistema financiero, en gran medida trabajamos para los bancos". El motivo es que para poder "castigar la deuda" es necesario iniciar proceso de cobranza judicial. Gutiérrez, V.; Maldonado, F., Diagnóstico de la actual judicatura civil: percepción social y análisis de trayectorias de causas, Santiago, Proyecto Reforma Procesal Civil de la Sociedad para la Cooperación Técnica Alemana GTZ-Chile, 2006, p. 13.

${ }^{21}$ Facultad de Derecho de la Universidad del Desarrollo (2013), p. 4. En otro informe se ha destacado: "90\% de los ingresos del año 2011 corresponden a ingresos de cobranza, de este 90\%, 41\% corresponde a ingresos de juicios ejecutivos y un $49 \%$ a gestiones preparatorias de la vía ejecutiva”: Ministerio de Justicia (2013), p. 8.

22 1) Un régimen de excepciones que desnaturaliza la actividad de ejecución; 2) Un sistema de recursos muy amplio, que permite llegar incluso a la Corte Suprema con los juicios ejecutivos; 3) La admisión de incidentes dilatorios; 4) La frecuente interpretación de normas según el criterio del "favor debitoris" o pro deudor: DE Hegedus; Romero (2010), pp. 540-541.

23 En el informe que hemos tenido a la vista se advierte, además, que las desviaciones estándares de todos los tipos de término son altas, lo que muestra una muy alta dispersión de los tiempos de término. Véase: DUCE et al. (2011), p. 29.

24 "Como se puede observar, en 2009 se terminaron 778.181 causas, de las cuales solamente 2.828 finalizaron con una sentencia definitiva. Estas últimas, que son las que realmente requieren la intervención de 
Entre los objetivos del Proyecto de nuevo CPC, según se puede leer del Mensaje (No 432-359), se encuentra esta aspiración por una mayor eficiencia que permita lograr salir de la actual situación que se reconoce insatisfactoria, especialmente en lo que dice relación con la realidad de nuestros juicios ejecutivos:

Por una parte se reconoce en el mensaje los altos niveles de retraso, un altísimo número de ingresos de causas que aumentan exponencialmente año tras año, especialmente con la presentación de demandas de cobro ejecutivo y preparaciones de la vía ejecutiva, lo que contribuye en la recarga del sistema. En efecto, se agrega, según las estadísticas, gran parte del total de las causas que conocen los tribunales civiles corresponden a juicios ejecutivos, "procedimiento que no tiene otra finalidad, sino obtener el cumplimiento compulsivo de lo ya ordenado por el propio juez, o por otro juez en un determinado procedimiento declarativo, o el cumplimiento de los denominados títulos ejecutivos".

Continúa el citado Mensaje señalando que la circunstancia de presentarse un real conflicto de relevancia jurídica en este procedimiento es meramente eventual y de exigua materialización en la práctica forense. "Sin embargo, el diseño de nuestro sistema actual judicializa necesariamente todos y cada uno de los procedimientos de ejecución, sin importar que exista o no oposición a dicha ejecución por parte del demandado. Incluso existiendo oposición, basada actualmente en una multiplicidad de excepciones, no se divisa razón alguna para que los restantes trámites del procedimiento, en su mayoría meramente administrativos, estén entregados a la labor del órgano jurisdiccional. Se desconcentra así al juez civil de su labor principal, que no debiera ser otra que la resolución de los conflictos de relevancia jurídica, que constituye en esencia la función jurisdiccional”.

"El impacto de esta labor administrativa realizada en sede judicial no se limita sólo a la sobrecarga de trabajo o al uso ineficiente de los recursos. Afecta particularmente $-y$ de manera trascendente- a la labor jurisdiccional que se realiza, la que se ve postergada por la carga de trabajo que implica a los jueces el asumir, por ejemplo, labores relacionadas al procedimiento de liquidación de bienes o pago de deudas". Este apunte no es menor, dado el reforzamiento de tareas y responsabilidades que tiene previsto el Proyecto para los jueces, con jueces que se quieren activos, directores del proceso ${ }^{25}$.

decisión del juez no terminan en sentencia. Esto se refleja en los tiempos de tramitación. Mientras las causas que terminan en "Téngase por no presentada la demanda", "Demanda sin movimiento", "No da curso a la demanda" y "Retiro de demanda", que suman el $97,7 \%$ de las causas, demoran un promedio de 55 días desde su ingreso hasta su término, las causas con sentencia requieren un promedio de 427 días": VV.AA. (2012), p. 21.

25 De la simple lectura del Proyecto se aprecia un importante reforzamiento de la carga de trabajo que, a diferencia de lo que ocurre en un régimen procesal escrito como el actual, los jueces no podrán delegarse ni 
Con todo, como se ha apuntado en otro informe, el enfoque de la solución a estos problemas no puede reducirse a consideraciones puramente estadísticas o numéricas, sino que "la necesidad de cambio obedece a razones de fondo y de entidad mucho más profunda que el simple colapso que se pudiese observar en los procedimientos ejecutivos y en el sistema de justicia civil y comercial en general". En el mismo sentido se agrega que la descongestión de los tribunales puede ser un objetivo, pero no puede considerarse el único norte, pues la reforma tiene "como misión desarrollar un sistema de ejecución que cumpla con los estándares propios de una sociedad desarrollada y garantice los derechos de sus ciudadanos" 26 .

Para ello el Proyecto en comento intenta recoger una propuesta moderna que se alinea con las tendencias de reforma introducidas en el derecho comparado, teniendo a la vista las mejores posibilidades para el derecho a la tutela judicial efectiva, respecto de lo cual la reforma al modelo de ejecución se apunta a nuestro parecer como una de las novedades más relevantes que se recogen en el Proyecto de nuevo CPC 27 . En efecto: "Como propósito conteste con los fines de la nueva justicia civil se cimenta el propósito de una ejecución civil más rápida, eficiente, cercana a la gente, y transparente. Esta nueva ejecución debiera contribuir sistémicamente al sistema: por un lado agilizar con profesionalismo eficiencia y mayor transparencia el cobro con la intervención de un tercero quien estará sujeto a control jurisdiccional permanente; por el otro permitirá que los tribunales se aboquen a labores netamente jurisdiccionales y sean liberados de tareas eminentemente administrativas" 28 .

esquivar dada la imposición de la regla de la inmediación. Si esto no se entiende, y no se acompaña la reforma procedimental de una reforma orgánica seria que parta por el correspondiente aumento del número de jueces, quedará irrealizada la aspiración de una respuesta más rápida para los justiciables, o bien -otra vez- se instalará una tremenda distancia entre lo prescrito por la ley como contenido para las audiencias y la deficitaria realidad práctica de las mismas, con sacrificio a la calidad del producto de la jurisdicción, lo que derechamente pondría en entredicho las promesas que se les están haciendo a las personas a propósito de la reforma procesal civil.

${ }^{26}$ Ministerio de Justicia (2013), p. 9.

27 Propuestas de reformas de modernización al modelo de ejecución que también se pueden apreciar en otros países, como acontece en España, donde según las últimas noticias que tenemos, se cuenta con un Proyecto de reforma que busca concretar importantes cambios en la materia. La doctrina científica, por su parte, ya hace sus aportaciones para mejorar un sistema que se considera altamente ineficiente, como por ejemplo, en las Jornadas Internacionales de Derecho Procesal "Hacia una gestión moderna y eficaz de la ejecución procesal”, organizadas por el Área de Derecho Procesal, del Departamento de Derecho de la Universidad Pompeu Fabra, realizadas en Barcelona los días 18 y 19 de noviembre. http://eventum.upf.edu/ event_detail/980/detail/jornadas-internacionales-de-derecho-procesal-lhacia-una-gestion-moderna-y-eficazde-la-ejecucion-pr Consultado con fecha 20/11/2013.

28 VV.AA. (2012), p. 9. 
La apuesta de cambio de la ejecución civil en el proyecto está dada fundamentalmente, tal como se expresa en el Mensaje, por la descentralización (o desjudicialización) de la ejecución, creando la figura del oficial de ejecución, bajo un control judicial permanente para la decisión de eventuales controversias ${ }^{29}$. Hace más de 6 años, siguiendo al profesor Ramos Méndez, escribíamos sobre la conveniencia de evitar caer en excesos o radicalismos: ni la privatización o completa desjudicialización de la ejecución (con el consiguiente abandono del control judicial de la misma), ni el aferrarse a una absoluta judicialización de cualquier actividad ligada a la ejecución puede entenderse como una apuesta inteligente y razonable ${ }^{30}$.

El Mensaje nos señala en este punto:

"[...] hemos optado por destacar su importancia, aspirando a instaurar en Chile un sistema que cumpla efectivamente con una ejecución eficaz, mediante el establecimiento de un procedimiento ejecutivo idóneo y rápido para el cobro de los créditos consignados en títulos a los que la ley otorga fuerza ejecutiva, sean jurisdiccionales o extrajurisdiccionales y que, al mismo tiempo, proteja y garantice los derechos de las partes".

"Con dicho objeto, se crea la figura del oficial de ejecución, como profesional encargado de llevar adelante todas las actuaciones de apremio, incluido el embargo, pero sometido siempre a un control permanente del juez. Asimismo, cada vez que exista oposición fundada a la ejecución o la interposición de tercerías, el procedimiento se judicializará debiendo ser el tema resuelto por el juez competente". Se apunta con esto a una mayor profesionalización de las tareas propias de la ejecución ${ }^{31}$.

${ }_{29}$ Cabe consignar la opinión contraria de la E. Corte Suprema de Chile en este punto, que en su informe al Proyecto (Oficio No 24-2013), de fecha 31 de enero de 2013, objeta la generación de esta figura del oficial de ejecución. Advirtiendo que se desconoce la regulación orgánica de los oficiales de ejecución propuestos, esta objeción la fundamentan en que las funciones que el proyecto le confiere a este oficial son netamente jurisdiccionales, y de allí la necesidad, sigue el informe, de que sean ejercidas por un funcionario sometido al régimen jurisdiccional, de manera que exista un control del mismo a través de la respectiva superintendencia disciplinaria. "En cuanto a la carga de trabajo de los tribunales civiles, no se advierte que la figura del oficial de ejecución vaya a influir significativamente en su disminución, considerando que las resoluciones de dicho funcionario son recurribles ante el juez y, por tanto, resultaría más adecuado derechamente establecer jueces de ejecución". Véase este informe sobre el PNCPC en http://www.ipdpchile.cl/wp-content/uploads/2011/01/ informe-corte-suprema-visa.pdf Consultado con fecha 11/11/2013.

30 Palomo (2007), p. 219.

31 Dentro de las opciones que se ofrecen en el derecho extranjero, la Comisión encargada de analizar el modelo a asumir en nuestro país destacó en sus conclusiones al menos dos aspectos muy importantes: 1) Debiera recogerse el modelo de profesión liberal, con la exigencia que se trate de un abogado; 2) Debiera imponerse un examen de conocimientos para acceder a la función, además de la realización de una práctica o pasantía, fundado en que será el oficial de ejecución el que se encargará directamente del análisis del título 
"Así, la ejecución constituirá, simplemente, un trámite administrativo bajo permanente control jurisdiccional, confiado a un funcionario denominado oficial de ejecución, cuya naturaleza, facultades, prohibiciones y régimen disciplinario serán regulados en una ley especial...”.

Más adelante, sigue el Mensaje: "Con ello, se quiere dar una señal de la importancia y entidad propia de la ejecución, pues más que tratarse de un procedimiento especial, el procedimiento ejecutivo es el llamado a dar eficiencia a la tutela declarativa, cuando ello sea necesario y en forma directa a la tutela de ejecución, en los demás casos".

"En esta nueva ejecución, la existencia de un título ejecutivo, ya sea por sentencia definitiva o por los demás títulos indubitados que la ley establece, dará paso simplemente a una solicitud de ejecución efectuada por el ejecutante ante el oficial mencionado, quien luego de verificar la concurrencia de los presupuestos y requisitos señalados en la ley, dará inicio al procedimiento de ejecución, pudiendo proceder inmediatamente, una vez notificado el ejecutado y ante la inexistencia del pago correspondiente, a efectuar los apremios que por ley procedan, incluido, el embargo de bienes concretos.

La ejecución se despachará mediante una resolución de carácter administrativa denominada decisión de ejecución, dictada por este oficial, respecto de la cual el ejecutado, debidamente notificado, podrá oponerse interponiendo para ante al juez competente una demanda de oposición a la ejecución que sólo podrá fundarse en muy limitadas causales. Exclusivamente en dicho caso la ejecución se judicializará y se suspenderá la realización de los bienes y el pago ante el oficial de ejecución, pero se mantendrán los embargos y demás medias de garantía vigentes.

Resuelta la oposición, si ella ha sido rechazada, se continuará con la ejecución ante el oficial de ejecución. Si, en cambio, se acogiera la demanda de oposición a la ejecución, se dejará tal ejecución sin efecto y se mandará alzar los embargos y las medidas de garantía que se hubieren adoptado, reintegrándose al ejecutado a la situación anterior al despacho de la ejecución...”.

Junto con lo anterior que apunta a la descentralización (o desjudicialización), también deben destacarse como medidas dirigidas a mejorar y dar mayor eficiencia a la ejecución civil en Chile, las que se concentran en los cambios de paradigmas funcionales o procedimentales necesarios, como bien se ha consignado por un

y de la concurrencia de los requisitos necesarios para iniciar un procedimiento de ejecución (artículo 426 del Proyecto). Véase: Ministerio de Justicia (2013), p. 19. La proliferación de títulos ejecutivos en leyes especiales es un antecedente que debe tenerse a la vista, y que no debe ser desatendido a la hora de tomarse en serio la determinación de quién va a ejercer como oficial de ejecución, puesto que pueden generar dudas sobre su calidad de tal, y este oficial debe estar perfectamente capacitado para decidir al respecto. 
autor, para satisfacer los estándares del debido proceso del mismo. "No parece adecuado plantear el derecho de acceso a la justicia, sin enfatizar igualmente el derecho a que, una vez transitado el palacio del proceso y haber obtenido la razón, ello quede solo declarado: ya porque termina difiriéndose su cumplimiento, ya porque el mismo modelo ejecutivo es ineficiente en poder acceder al patrimonio a ejecutar, ya porque se termina entendiendo que al menos la victoria que obtuvo la otrora parte demandante, ahora acreedor satisfizo su derecho de acción" 32 .

En consecuencia, en cuanto a los aspectos funcionales o procedimentales existe un cambio de paradigmas y "principios"33 que van dejando marcas en el diseño que se propone, como lo son el deber de transparencia patrimonial y colaboración por parte del deudor (arts. 444-448 del Proyecto) y todos dirigidos a garantizar una tutela judicial efectiva. Así, por ejemplo, se establece como manifestación de un deber específico de cooperación por parte del deudor que, una vez notificado de la decisión de ejecución, "para los efectos del embargo, tiene la obligación de declarar bajo juramento ante la oficial de ejecución en forma completa y veraz los bienes suficientes de su patrimonio..." (art. 444), declaración del ejecutado sobre su patrimonio con el contenido y detalle previsto también en la normativa proyectada. Agregándose que "en caso que el ejecutado no efectúe oportunamente la declaración jurada de bienes, incluya en ella bienes de terceros, omita bienes susceptibles de embargo o no dé a conocer las cargas y gravámenes que sobre ellos pesaren, el juez podrá imponer sanciones conminatorias de hasta veinte unidades tributarias mensuales, las que serán a beneficio del ejecutante" (art. 446) ${ }^{34}$. Esta pareciera ser la tendencia más moderna en las regulaciones procesales vigentes, especialmente en Europa.

También se regula la investigación del patrimonio del ejecutado (art. 447), para el caso que se pueda desprender que la declaración de éste no sea veraz o bien ésta no se haya realizado:

\footnotetext{
32 Pérez-Ragone (2013), p. 286.

33 En materia de principios de la ejecución civil, véase especialmente: Pérez-Ragone (2011), pp. 685 y ss. También, referido específicamente a la transparencia patrimonial: PéreZ-RaGOnE; SilVA (2009), pp. 79-115.

${ }^{34}$ No conforme con ello, se agrega, en la misma norma propuesta: "Para fijar la cuantía de las sanciones, se tendrá en cuenta el monto adeudado, la resistencia a la presentación oportuna, completa y veraz de la declaración de los bienes y la capacidad económica del ejecutado, pudiendo modificarse o dejarse sin efecto el apremio económico en atención a su ulterior conducta y a las alegaciones que pudiere efectuar para justificarse. Estas sanciones podrán repetirse todas las veces que sea necesarias bajo los apercibimientos antes señalados. Se conformará una nómina pública con el nombre de aquéllos ejecutados que hayan sido sancionados por incumplimiento de alguna de las obligaciones establecidas en este artículo" (art. 446).
} 
"En caso de incumplimiento de la declaración de bienes o insuficiencia del embargo, el oficial de ejecución estará facultado para recabar de personas naturales y jurídicas y organismos y registros públicos, información que no esté legalmente protegida por reserva o secreto, acerca de bienes del ejecutado susceptibles de ser embargados. En caso de negativa injustificada del requerido, el oficial de ejecución deberá requerir autorización judicial para realizar la investigación”.

Añadidamente, y entendemos que también con carácter complementario y para el caso que lo anterior fracase, se consagra un deber general de colaboración de todas las personas y entidades públicas y privadas, que estará obligadas a prestar su colaboración en las actuaciones de ejecución, y entregar al oficial de ejecución o al tribunal cuantos documentos y datos tengan en su poder, sin más limitaciones que las que imponen el respeto a los derechos fundamentales o a los límites que, para casos determinados, expresamente impongan las leyes (art. 448).

Nota aparte requiere, aunque sea sucinta por las limitaciones y naturaleza del informe encargado, la incorporación de la fórmula de la ejecución provisional de las sentencias condenatorias no firmes, mecanismo sobre el cual ya hemos escrito en otros lugares ${ }^{35}$, en donde el Proyecto realiza una apuesta, que siguiendo otros modelos extranjeros (el español, por ejemplo), es tan contundente como arriesgada.

En lo que dice relación con la ejecución provisional de las sentencias condenatorias en la propuesta de nuevo CPC como mecanismo a través del cual se pretende implementar un giro radical a la situación vigente. El Proyecto, implementando un giro notable con la situación vigente, opta por conceder a la parte gananciosa el derecho a pedir y obtener de manera inmediata la ejecución provisional de la sentencia condenatoria dictada en la primera instancia que no estén firmes. Se busca, como bien se ha puesto de relieve en otros lugares, acortar el horizonte temporal de una respuesta jurisdiccional eficaz. Y se busca también, de paso, evitar algunas malas prácticas y reducir el número de recursos interpuestos con ánimo exclusivamente dilatorio y abuso procesal. Confiando y apostando por el trabajo de esos tribunales que, en estas nuevas condiciones y estructura formal, y con los debidos resguardos procedimentales y orgánicos, debieran estar en condiciones de entregar un producto de mayor calidad.

¿Se ignoran los riesgos de implementar un cambio de esta naturaleza? No queda muy claro, pero aun conociéndolos, se asume por sus promotores más entusiastas que los beneficios de consagrarla son mayores que sus posibles inconvenientes. El problema, en todo caso, no pasa por recoger o no el instituto, sino que, al igual que lo que acontece con la cuestión de las potestades oficiosas de los jueces, lo más importante está en el cómo se termina recepcionando por el legislador, y en esa línea se ha dicho (hemos

35 Palomo (2012), pp. 197-217. También véase: Palomo (2013). 
dicho) que existen fórmulas menos riesgosas y más equilibradas entre los legítimos intereses de la parte provisionalmente gananciosa y la parte provisionalmente perdidosa. En efecto, la clave debiera estar en que el legislador opere prudente y responsablemente, logrando un punto de equilibrio entre la búsqueda del fortalecimiento de lo fallado en la primera instancia y la situación de eventual indefensión en que puede dejar al ejecutado provisional.

¿Qué nos ofrece la regulación propuesta en Chile? El primer aspecto que marca la regulación está en el hecho que la ejecución provisional se establece sin necesidad de constituir fianza o caución inicial, sin necesidad de adelantar cantidad alguna, con todo el riesgo que eso pueda suponer. De la mano con lo anteriormente anotado, el segundo punto central en la propuesta que se plantea entre nosotros es que no se reconocen a los jueces potestades que le permitan ponderar las circunstancias del caso, como sí acontece en otras regulaciones del Derecho Comparado dónde está autorizado para tenerlas en consideración y de ese modo evitar la materialización de eventuales perjuicios que resulten ser irreparables para el ejecutado provisional. El tercer aspecto central es que se plantea en el Proyecto una ejecución provisional con una posibilidad de oposición bastante limitada, tanto que, tratándose de sentencias condenatorias a pagar sumas de dinero, la oposición que pretenda formularse solamente podrá decir relación con concretas actuaciones ejecutivas del procedimiento de apremio. Además, al oponerse en este caso, el ejecutado deberá indicar otras medidas $\mathrm{o}$ actuaciones ejecutivas que sean posibles y no provoquen situaciones similares a las que causaría, a su juicio, la medida a la cual se opone.

También merece mención aparte la situación de la ejecución laboral, cuyo diseño que sigue el modelo judicial, con tribunales y jueces especializados en la materia, dicho eufemísticamente, ha evidenciado no estar funcionando eficientemente, sacrificando en importante medida las buenas "estadísticas" de tiempos de duración promedio que se han logrado imponer en lo que dice relación con los procedimientos declarativos. Derechamente, la ejecución laboral concentrada en tribunales de ejecución (Juzgados de cobranza laboral y previsional) ha fracasado rotundamente. De hecho, informes que se han elaborado sobre la materia, junto con destacar el buen funcionamiento de la reforma a la Justicia laboral, consignan que se observan desde hace tiempo graves problemas en relación a la cobranza de los créditos laborales y previsionales, el funcionamiento de los juzgados de ejecución, junto con la incomodidad de los propios jueces que no consideran estar realizando una labor jurisdiccional ${ }^{36}$. Además, como bien lo ha expresado con

\footnotetext{
36 Se ha dicho en este sentido que la exitosa reforma a la justicia laboral ha tenido su talón de Aquiles en la ejecución anclada en paradigmas orgánicos y funcionales ineficientes: "Este modelo judicializado vigente en
} 
acierto Pérez-Ragone, por un lado, el patrimonio del ejecutado no está dentro del despacho del juez y, por el otro, la ejecución necesita de mucha actividad y medidas en terreno: la ejecución, necesariamente, funciona externamente ${ }^{37}$. Se van instalando también en esta sede preguntas tales como: ¿Qué es lo que quieren hacer los jueces? ¿Qué es lo que otros pueden hacer más eficientemente?

Así se ha puesto de relieve en un relativamente reciente informe ${ }^{38}$ que pretende sentar las bases para la reforma al sistema de ejecución en el proceso laboral, a pocos años de la entrada en vigencia del nuevo modelo de justicia laboral. Otra vez en Chile, al parecer, tendremos que recurrir al mecanismo de la reforma de la reforma que tanto deslegitima el trabajo legislativo que muchas veces no se efectúa con todo el rigor, estudio, asesoría y deliberación que impone una tarea tan delicada e incidente en las personas como ésta.

"La reforma procesal laboral y previsional no consideró una reforma estructural del modelo del juicio ejecutivo y los esfuerzos se agotaron en trasladar el problema a los nuevos juzgados de cobranza, en los que se reproducen parte importante de los problemas que en su momento justificaron la reforma. Los JCLP se crearon para resolver el problema de sobrecarga de los juzgados laborales como consecuencia de la cobranza previsional, en las jurisdicciones en las que dicha cobranza se concentra. Ello supuso un gran alivio para la justicia declarativa, pero no mejoró la etapa de cumplimiento de las sentencias".

De hecho, agrega el informe citado, "la función del JCLP en Santiago está monopolizada por el cobro de cotizaciones previsionales (90\%). El cumplimiento de las sentencias, incluidas las antiguas, alcanza sólo el 5\% del ingreso, al 2011.

No obstante el bajo impacto de los cumplimientos de las sentencias laborales en el ingreso de los JCLP, por su complejidad y carga administrativa representan un importante volumen de trabajo para el JCLP (giro de cheques, liquidaciones, certificaciones y resoluciones firmadas por juez). De las cobranzas terminadas con éxito el 2011, el 97\% son previsionales, lo que habla de un mejor desempeño en este tipo de cobranzas. Los mayores déficit se producen en la ejecución de las sentencias (1\% cumplimiento laboral)".

materia civil se replica en la ejecución laboral, donde incluso el proceso ejecutivo debiera ser funcionalmente más expedito", pero nos encontramos con "colapso, ineficiencia, descontento de los actores del sistema. Pérez-Ragone (2013), p. 286.

37 Pérez-Ragone (2013), p. 286.

38 VV.AA. (2013), pp. 7 y ss. 
A su turno, entre los principales defectos del modelo procedimental actual en relación a la ejecución laboral se apuntan la aplicación supletoria de casi todas las normas relativas a la ejecución de bienes que contempla el Código de Procedimiento Civil vigente, que "no se condicen con la eficacia que pretende la reforma" 39 . A lo anterior se suman, por ejemplo, instrumentos de ejecución obsoletos y la "inexistencia de una regulación adecuada acerca de la transparencia patrimonial y de una sanción eficaz asociada" ${ }^{40}$. Respecto a las propuestas que se manejan para esta sede jurisdiccional, me remito al informe que puede consultarse sin dificultad en el sitio web del Instituto de Estudios Judiciales de Chile Hernán Correa de la Cerda ${ }^{41}$, pero en todo caso destacamos que, si bien contempla propuesta para una fase intermedia, apunta con claridad hacia la desjudicialización progresiva de la cobranza laboral, en un sentido muy similar a lo que se recoge en la propuesta de nuevo Código Procesal Civil.

\section{REFORMAS DEL PROCEDIMIENTO MONITORIO42}

Como ya lo hemos dejado sentado antes, una de las principales preocupaciones que el legislador ha tenido en Chile (y no sólo en Chile) ${ }^{43}$ en las reformas proce-

39 VV.AA. (2013), p. 10.

40 VV.AA. (2013), p. 10.

${ }^{41} \mathrm{http}: / / w w w . i e j . c l / 2012 /$ wp-content/uploads/2013/06/Reforma-Ejecuci\%C3\%B3n-Laboral.pdf Consultado con fecha $9 / 11 / 2013$.

42 Reformas del proceso monitorio

1. Si en tu país existe proceso monitorio, responde a los siguientes puntos:

1.1. ¿Dónde está regulado y cuál es la fecha de la regulación?

[por favor, si te es posible adjunta la regulación]

1.2. Si existen datos estadísticos:

1.2.1. ¿Cuántos procesos monitorios hubo en el año más próximo al actual?

1.2.2. Indica el grado de eficacia de este tipo de proceso, esto es, los que acaban en pago o en ejecución (si es posible, en cifras absolutas y relativas).

1.3. ¿Qué tipo de proceso monitorio (documental o puro) se prevé?

1.4. ¿Para qué tipo de reclamaciones (dinerarias, no dinerarias, etc.) está previsto?

1.5. Intervención de abogado: ¿obligatoria o voluntaria?

1.6. Tipo de oposición posible: genérica o plenamente motivada.

1.7. Relación entre el proceso monitorio y el declarativo posterior: describe en qué medida el juicio declarativo posterior está vinculado por lo alegado (actor) u opuesto (demandado) en el monitorio.

1.8. Indica los tres problemas más importantes que plantea el proceso monitorio en tu país.

2. Si en tu país no existe proceso monitorio, responde a los siguientes puntos:

2.1. Indica por qué no existe este tipo de proceso de tutela del crédito.

2.2. Indica si la doctrina científica de tu país ha reclamado su introducción.

2.3. Indica si han habido propuestas normativas de su introducción y, en caso de respuesta afirmativa, describe en qué consistían (tipo de proceso monitorio, etc.).

43 Véanse interesantes trabajos en Nieva et al. (2013). 
sales en curso o en proyección ha sido la ejecución. Pues bien, en este contexto se enmarca también el esfuerzo legislativo de incorporar la fórmula del procedimiento monitorio entre nosotros, y las breves líneas que siguen estarán dirigidas exclusivamente a dar cuenta de la situación del monitorio en nuestro país, intentando seguir la guía entregada por el profesor Picó al momento de hacernos el encargo.

En Chile el procedimiento monitorio se introdujo en el ordenamiento jurídico con la aprobación del "nuevo" Código Procesal Penal a cuyas leyes asociadas ya hicimos referencia en este texto. Sin embargo, debemos destacar que se trata de un monitorio sui generis. Básicamente, se aplica para la tramitación de faltas en que el fiscal solicita, solamente, pena de multa (art. 392 CPP) ${ }^{44}$. El juez, si lo considera suficientemente fundado, debe acoger de inmediato (esta sería la característica monitoria, en que no existe una efectiva contradicción ex ante). Por su parte, el imputado puede oponerse en un plazo de 15 días o de lo contrario se entiende que está conforme con la decisión judicial. En caso de oponerse, se continuará el proceso mediante el procedimiento simplificado aplicable a la falta (arts. 388 y ss). En sede penal se ingresaron 636.660 causas, y terminaron por procedimiento monitorio 67.494 causas $(10,6 \%)^{45}$.

En sede laboral, donde procede respecto a despidos por escasa cuantía y, especialmente, despidos ilegales a trabajadoras con fuero maternal, y aunque fue recepcionado en diversa, desde la reforma de la Ley No 20.260 es, si cabe,

44 Artículo 392.- Procedimiento monitorio. Se aplicará el procedimiento monitorio a la tramitación de las faltas respecto de las cuales el fiscal pidiere sólo pena de multa. En el requerimiento señalado en el artículo precedente el fiscal indicará el monto de la multa que solicitare imponer. Si el juez estimare suficientemente fundado el requerimiento y la proposición relativa a la multa, deberá acogerlos inmediatamente, dictando una resolución que así lo declare. Dicha resolución contendrá, además, las siguientes indicaciones:

a) La instrucción acerca del derecho del imputado de reclamar en contra del requerimiento y de la imposición de la sanción, dentro de los quince días siguientes a su notificación, así como de los efectos de la interposición del reclamo; b) La instrucción acerca de la posibilidad de que dispone el imputado en orden a aceptar el requerimiento y la multa impuesta, así como de los efectos de la aceptación, y c) El señalamiento del monto de la multa y de la forma en que la misma debiere enterarse en arcas fiscales, así como del hecho que, si la multa fuere pagada dentro de los quince días siguientes a la notificación al imputado de la resolución prevista en este inciso, ella será rebajada en $25 \%$, expresándose el monto a enterar en dicho caso.

Si el imputado pagare dicha multa o transcurriere el plazo de quince días desde la notificación de la resolución que la impusiere, sin que el imputado reclamare sobre su procedencia o monto, se entenderá que acepta su imposición. En dicho evento la resolución se tendrá, para todos los efectos legales, como sentencia ejecutoriada. Por el contrario, si, dentro del mismo plazo de quince días, el imputado manifestare, de cualquier modo fehaciente, su falta de conformidad con la imposición de la multa o su monto, se proseguirá con el procedimiento en la forma prevista en los artículos siguientes. Lo mismo sucederá si el juez no considerare suficientemente fundado el requerimiento o la multa propuesta por el fiscal.

45 Fuente: Justicia, Informe anual, INE año 2012. 
más "original", puesto que por las especialidades propias de este ordenamiento existe una fase administrativa ante la Inspección del Trabajo ${ }^{46} \mathrm{y}$, a su vez, una fase propiamente monitoria ante el Juez de Letras del Trabajo. Interpuesta una demanda monitoria, el juez podrá acoger o rechazar sin mayor contradictorio, $y$ la particularidad más significativa del monitorio laboral es una tercera opción que es llamar a una audiencia. Reproducimos a continuación la normativa pertinente, comprendida en el Código del Trabajo, constriñendo y reuniendo los incisos que dan contenido a los respectivos artículos por razones de espacio:

Artículo 496.- Respecto de las contiendas cuya cuantía sea igual o inferior a diez ingresos mínimos mensuales, sin considerar, en su caso, los aumentos a que hubiere lugar por aplicación de los incisos quinto y séptimo del artículo 162; y de las contiendas a que se refiere el artículo 201 de este Código, se aplicará el procedimiento que a continuación se señala ${ }^{47}$.

Artículo 497.- Será necesario que previo al inicio de la acción judicial se haya deducido reclamo ante la Inspección del Trabajo que corresponda, la que deberá fijar día y hora para la realización del comparendo respectivo, al momento de ingresarse dicha reclamación. Se exceptúan de esta exigencia las acciones referentes a las materias reguladas por el artículo 201 de este Código. La citación al comparendo de conciliación ante la Inspección del Trabajo se hará mediante carta certificada, en los términos del artículo 508, o por funcionario de dicho organismo, quien actuará en calidad de ministro de fe, para todos los efectos legales. En este caso, deberá entregarse personalmente dicha citación al empleador o, en caso de no ser posible, a persona adulta que se encuentre en el domicilio del reclamado. Las partes deberán concurrir al comparendo de conciliación con los instrumentos probatorios de que dispongan, tales como contrato de trabajo, balances, comprobantes de remuneraciones, registros de asistencia y cualesquier otros que estimen pertinentes. Se levantará acta de todo lo obrado en el comparendo, entregándose copia autorizada a las partes que asistan.

Artículo 498. - En caso que el reclamante no se presentare al comparendo, estando legalmente citado, se pondrá término a dicha instancia, archivándose los antecedentes. Sin perjuicio de lo señalado en el inciso anterior, el trabajador podrá accionar judicialmente conforme a las reglas del procedimiento de aplicación general regulado en el Párrafo $3^{\circ}$ del presente Título.

\footnotetext{
46 Sobre esta reclamación administrativa previa véase: ACADEMIa Judicial De Chile (2008), p. 123.

47 El debate parlamentario, bien se ha dicho, da cuenta que la idea del procedimiento monitorio en sede laboral va en la línea de simplificar, facilitar y acelerar la respuesta, para que los trabajadores puedan demandar determinadas sumas de dinero. Pereira (2010), p. 22.
} 
Artículo 499.- Si no se produjere conciliación entre las partes o ésta fuere parcial, como asimismo en el caso que el reclamado no concurra al comparendo, el trabajador podrá interponer demanda ante el juez del trabajo competente, dentro del plazo establecido en los artículos 168 y 201 de este Código, según corresponda. La demanda deberá interponerse por escrito y contener las menciones a que se refiere el artículo 446 de este Código. Deberá acompañarse a ella el acta levantada en el comparendo celebrado ante la Inspección del Trabajo y los documentos presentados en éste. Esta exigencia no regirá en el caso de la acción emanada del artículo $201^{48}$.

Artículo 500.- En caso que el juez estime fundadas las pretensiones del demandante, las acogerá inmediatamente; en caso contrario las rechazará de plano. Para pronunciarse, deberá considerar, entre otros antecedentes, la complejidad del asunto que se somete a su decisión, la comparecencia de las partes en la etapa administrativa y la existencia de pagos efectuados por el demandado. En caso de no existir antecedentes suficientes para este pronunciamiento, el tribunal deberá citar a la audiencia establecida en el inciso quinto del presente artículo. Las partes sólo podrán reclamar de esta resolución dentro del plazo de diez días hábiles contado desde su notificación, sin que proceda en contra de ella ningún otro recurso. La notificación al demandado se practicará conforme a las reglas generales. En todo caso, en la notificación se hará constar los efectos que producirá la falta de reclamo o su presentación extemporánea. Presentada la reclamación dentro de plazo, el juez citará a las partes a una audiencia única de conciliación, contestación y prueba, la que deberá celebrarse dentro de los quince días siguientes a su presentación. Si el empleador reclama parcialmente de la resolución que acoge las pretensiones del trabajador, se aplicará lo establecido en el artículo $462^{49}$.

Artículo 501.- Las partes deberán asistir a la audiencia con todos sus medios de prueba y, en caso de comparecer a través de mandatario, éste deberá estar expresamente

48 Esta norma ha generado problemas prácticos ligados a la generación de la prueba al momento de la presentación misma de la demanda. En efecto, la ley sólo obliga al actor a presentar los documentos en los cuales conste la intervención ante la Inspección del Trabajo, como también los que hubiese acompañado en dicha sede administrativa. Con estos antecedentes debe resolver el tribunal. No existe la carga de acompañar toda la prueba o al menos individualizarla íntegramente en la demanda, lo que ha causado problemas en la práctica forense, generándose una importante cantidad de resoluciones que acogen a tramitación la demanda monitoria y citan a la audiencia de conciliación, contestación y prueba.

49 "El juez puede acoger la demanda, rechazarla o citar a una audiencia cuando estime que no tiene antecedentes para emitir pronunciamiento. Las primeras dos alternativas son propias de este tipo de procedimiento. La tercera, introducida por la Ley No 20.260, se aparta de la concepción propia de los procedimientos monitorios, desde que es ajena a la lógica esencial de este tipo de arbitrios, conforme a la cual sólo la oposición de parte activa la fase contradictoria del juicio y de no producirse ésta, la causa simplemente concluye, en el caso de rechazo de la demanda, o se genera -si se acoge- la pretensión de un título ejecutivo". ACADEMIA Judicial DE CHILE (2008), p. 126. 
revestido de la facultad de transigir ${ }^{50}$. La audiencia tendrá lugar con sólo la parte que asista. El juez deberá dictar sentencia al término de la audiencia, la que deberá contener las menciones señaladas en los números 1, 2, 5, 6 y 7 del artículo $459^{51}$.

Artículo 502.- Las resoluciones dictadas en el procedimiento monitorio serán susceptibles de ser impugnadas por medio de todos los recursos establecidos en este Código, con excepción del recurso de unificación de jurisprudencia contenido en los artículos 483 y siguientes.

De acuerdo a la información no muy sistemática y uniforme que hemos podido tener a la vista para el presente informe, utilizando como fuente principal los datos estadísticos publicados por las Oficinas de Defensoría Laboral (ODL), siguiendo también muy especialmente un informe comunicado por el magistrado Álvaro Flores $^{52}$, podríamos concluir que las cifras del procedimiento monitorio laboral se pueden descomponer del siguiente modo: a) Duración nacional promedio: 35 días (en comparación con los 81 días promedio del procedimiento ordinario, o los 82 días del procedimiento de tutela); b) Del ingreso, un 39\% en promedio son procedimientos monitorios (este dato debe compararse con el $47 \%$ que representa el procedimiento ordinario); c) Según el tipo de término de los asuntos, la información se desglosa de este modo: 1) en un $13 \%$ de los casos se acoge la demanda monitoria; 2) en un $34 \%$ se termina por conciliación; 3) un $28 \%$ por

\footnotetext{
50 El diseño ha generado críticas de algún sector desde la perspectiva del derecho al debido proceso en general y el derecho a la prueba en particular. En efecto, por el diseño procedimental no es posible solicitar cualquier medio de prueba (por ejemplo, una inspección personal del tribunal o la solicitud de una pericia), limitándose -en los hechos- las pruebas a la documental, la testimonial y la confesional; ni tampoco la ley autoriza a dar paso a una audiencia para la práctica de alguna prueba, cuando las circunstancias así lo pudieran sugerir. La solución de los tribunales ha estado en reivindicar la celeridad que entienden está detrás de esta regulación.

51 Se ha objetado también esta norma: "Estimamos, sin embargo, que la señalada disposición ha omitido la necesaria motivación del fallo, pues reduce la sentencia al deber de identificar la fecha y lugar en que se expide, la singularización de las partes, la enunciación de las normas jurídicas, la decisión de lo controvertido y el pronunciamiento sobre las costas. Se soslaya de este modo la circunstancia que el proceso deviene en una controversia de hecho, con un espacio probatorio, con el aporte de las partes para la formación de la convicción a favor de las pretensiones de las que necesariamente el juzgador deberá hacerse cargo en la resolución final”. ACADEMia Judicial de Chile (2008), p. 129.

52 En las XIX Jornadas Nacionales de Derecho del Trabajo y de la Seguridad Social, realizadas en Valdivia los días 10, 11 y 12 de mayo de 2012, organizadas por la Sociedad Chilena de Derecho del Trabajo y la Seguridad Social y la Facultad de Ciencias Jurídicas y Sociales de la Universidad Austral de Chile. En su ponencia "Evaluación de la reforma procesal laboral", el juez Flores exhibió estadísticas nacionales y de su propio Juzgado. http://www.derecho.uach.cl/actividad.php?pag=56\&id=36. Consultado el 11/11/2013.
} 
sentencia, un $9 \%$ por avenimientos, aproximadamente, sin perjuicio de otras formas de término. En las audiencias monitorias el $65 \%$ termina por conciliación ${ }^{53}$.

En mayor consonancia con la tradición de este procedimiento y con los modelos de Derecho comparado, la reforma procesal civil también incorpora como novedad el procedimiento monitorio (arts. 539-550 PNCPC). Se trata del mecanismo que ha de convertirse en el medio más idóneo para reclamar el pago de obligaciones que no constan en un título ejecutivo. Así lo anuncia el Mensaje del Proyecto:

"Siguiendo la línea de otros ordenamientos, y atendiendo que se suprimen las gestiones preparatorias de la vía ejecutiva, destaca en el Proyecto la regulación del monitorio como procedimiento especial de naturaleza declarativa, sin base documental, pero con un límite de cuantía de quinientas Unidades Tributarias Mensuales, para el cobro de obligaciones que, no constando en un título ejecutivo, sean líquidas o bien consistan en hacer una cosa determinada, se encuentren vencidas, sean actualmente exigibles y siempre que la acción para cobrarlas no se encuentre prescrita”.

Con todo, tratándose del cobro de obligaciones de dar que consten en títulos de créditos y de obligaciones de hacer que constando en un documento, consistan en la suscripción de un documento o Constitución de una obligación, no tendrá lugar esta limitación de cuantía.

En el evento que el deudor no pague, no comparezca o no formule oposición, se le tendrá por condenado al pago de la obligación reclamada. La resolución que así lo declare tendrá la fuerza de sentencia definitiva firme y servirá de título suficiente para su ejecución.

En caso contrario, esto es, si el deudor paga o bien formula oposición de fondo, el tribunal declarará terminado el procedimiento monitorio, quedando sin efecto de pleno derecho el requerimiento de pago y la resolución que dio lugar al procedimiento.

Con el objeto de evitar el uso meramente dilatorio, se establece en forma expresa que la oposición del demandado configurará y delimitará necesariamente el objeto del juicio declarativo posterior que decidiere iniciar el demandante, no pudiendo discutirse en él sobre otras cuestiones diversas a la existencia de la obligación y a las alegaciones y excepciones planteadas por el deudor en el procedimiento monitorio".

En consecuencia, los requisitos para acudir a un monitorio civil serán: que se trate de una cantidad líquida, o fácilmente liquidable, de dinero; deben ser

53 Véase también sobre el funcionamiento efectivo de la reforma procesal laboral en Chile: LiLlo y AlCAínO (2013). 
obligaciones vencidas y actualmente exigibles; la deuda no debe haber prescrito y, finalmente, el Proyecto contempla, como en otros modelos de Derecho comparado, un límite asociado a la cuantía por quinientas Unidades Tributarias Mensuales (40.000 U\$ aproximadamente). El artículo 539 del Proyecto define además el ámbito de aplicación de este procedimiento: será un medio idóneo para reclamar el pago de obligaciones que no constan en un título ejecutivo ${ }^{54}$.

El monitorio proyectado, que al tenor del artículo 540 inciso final tiene base documental al establecer que "se deberá acompañar a la demanda todos los documentos que le sirvieren de fundamento" 55 , principiará con una "demanda monitoria", que deberá ser patrocinada por un abogado ${ }^{56}$, lo que nos parece razonable y adecuado. Ésta deberá contener tanto los requisitos comunes a toda demanda como las formalidades específicas previstas en el artículo 540 del Proyecto. A saber: la singularización de la deuda, el valor o cuantía de la obligación y lo que podríamos denominar el aviso que en el supuesto de no pagar, no comparecer o no oponerse, se le va a dar por condenado al pago de la obligación reclamada.

La esencia del procedimiento monitorio civil chileno responde a la opción tradicional, y por lo mismo está en que, junto con las formalidades habituales de una petición simple, el actor debe solicitar que se requiera al deudor para que en un plazo no superior a quince días pague la obligación, más los intereses, reajustes y costas. Y se le avise que en el supuesto de no pagar, no comparecer o no oponerse, se le va a dar por condenado al pago de la obligación reclamada.

Ante el requerimiento de pago, el deudor tiene diversas opciones: en primer lugar, podrá pagar total o parcialmente la deuda más intereses y costas. En segundo lugar, el deudor puede oponerse (la oposición debe ser plenamente motivada, señalando los fundamentos de hecho y de derecho de las alegaciones o excepciones que opone), garantizándose de este modo el derecho de defensa y el debido proceso; además, deberá acompañar a su escrito los documentos y señalar los demás medios de prueba de que se valdrá en los términos previstos

\footnotetext{
54 Se sabe que el objetivo del monitorio es generar en forma rápida un título ejecutivo de donde no lo hay, para fortalecer la tutela del crédito. Como bien lo ha dicho el profesor Jordi Delgado, "se está rediseñando el paradigma actual en que se llama a confesar la deuda y si conseguimos que el deudor aparezca, le basta con decir que no, para que deba tramitarse un juicio declarativo en el que quizás no hay muchos elementos de contradicción y la deuda figura diáfanamente en un documento".

55 Adjuntos a la demanda se deberán acompañar los documentos que evidencien la deuda.

56 La intervención del abogado es obligatoria.
} 
por el artículo 273 (art. 545) y, finalmente, podrá mantenerse inactivo y, de este modo, se generará de inmediato el título ejecutivo, que es precisamente lo que persigue el acreedor ${ }^{57}$.

En cuanto a la relación entre el procedimiento monitorio y el declarativo posterior, cabe señalar, tal cual lo adelanta el Mensaje del Proyecto, que esta vinculación es total y absoluta. No se permite la incorporación de nuevas pretensiones, alegaciones, ni excepciones, por ninguna de las partes. Así queda claramente expresado en el artículo 548 del Proyecto.

Ya terminando este informe en general, y también lo ligado a las reformas en materia de procedimientos monitorios, y al hilo de la pregunta que se formula sobre cuáles son los tres problemas más importantes que plantea el proceso monitorio en Chile, cabría identificar los siguientes:

a) El primer problema es la falta de conocimiento cultural o, dicho en otras palabras, escaso entendimiento de la técnica monitoria como instrumento para la mejora de la tutela judicial del crédito $^{58}$. En efecto, no se conoció su origen como mecanismo de agilidad crediticia y hoy se asocia solamente a un procedimiento breve y concentrado con oposición reducida.

b) El segundo problema es que, dado que si bien conocemos en Chile del monitorio pero no en su sentido más tradicional, no siempre resulta un mecanismo de descongestión de los tribunales (al punto que debiera serlo) y prácticamente prevé una fase de conocimiento más extensa de lo que considera un monitorio civil clásico.

c) El tercer problema podría decir relación con aspectos de diseño en la reforma procesal civil que pueden terminar limitando la eficacia del mismo, como la incorporación de una cuantía máxima o la falta de sanción a la oposición infundada o fraudulenta cuyo único objetivo es dilatar el procedimiento, con manifiesta infracción a la buena fe que se pretende instalar reforzada como principio del nuevo modelo procesal.

\footnotetext{
57 Reiteramos que se puede revisar el texto del PNCPC y las normas que recogen la regulación propuesta para el procedimiento monitorio civil: http://rpc.minjusticia.gob.cl/media/2013/04/Proyecto-de-Ley-deNuevo-Codigo-Procesal-Civil.pdf. Consultado con fecha 11/11/2013.

58 BONET (2008), p. 482.
} 


\section{BiBLIOGRAFÍA CITADA}

Academia Judicial de Chile (2008): Manual de Juicio del Trabajo (Santiago, LOM Ediciones).

BoneT, J. (2008): "Eficiente implementación del procedimiento monitorio en Iberoamérica", en CABEZÓN, A. (Coordinadora): Justicia civil: perspectivas para una reforma en América Latina (Santiago, CEJA-JSCA). Véase en http://www. cejamericas.org/index.php/biblioteca/publicaciones-ceja.html [Consultado con fecha $11 / 11 / 2013]$.

De Hegedus, M.; Romero, A. (2010): "La ejecución civil: Ponencia general", en Tavolari, R. (Coordinador): Derecho procesal contemporáneo: ponencias de las XXII Jornadas Iberoamericanas de Derecho Procesal. Tomo I (Santiago, Ed. Jurídica de Chile/Punto Lex/Thomson Reuters).

Duce, M.; Hernández, C.; Medrano, A.; Vargas, M. (2011): Estudio de análisis de trayectoria de las causas civiles de Santiago (Santiago, CEJA-JSCA). Véase en http://rpc.minjusticia.gob.cl/media/2013/04/Estudio-Trayectorias-CausasCiviles-en-Tribunales-Civiles-Santiago.pdf [Consultado con fecha 4/11/2013].

Facultad de Derecho de la Universidad del Desarrollo (2013): Anteproyecto de reforma del Código de Procedimiento Civil (Santiago, UDD).

García, J.; LetUria, F. (2006): "La justicia civil y comercial chilena en crisis: bases para el diseño de su reforma”, Informe Político, No 95 (Libertad y Desarrollo).

Gutiérrez, V.; Maldonado, F. (2006): Diagnóstico de la actual judicatura civil: percepción social y análisis de trayectorias de causas (Santiago, Proyecto Reforma Procesal Civil de la Sociedad para la Cooperación Técnica Alemana GTZChile).

Ministerio de Justicia (2013): Informe final Panel de Expertos para la creación de un modelo orgánico de oficial de ejecución (Santiago, Reforma Procesal Civil) visitado en http://rpc.minjusticia.gob.cl/media/2013/07/Informe-FinalModelo-Organico.pdf [Consultado con fecha 9/11/2013].

Nieva, J.; Rivera, R.; Colmenares, C.; Correa, J. (2013): El procedimiento monitorio en América Latina: Pasado, presente y futuro (Bogotá, Ed. Temis).

Palomo, D. (2010): Reforma Procesal Civil: Oralidad y poderes del juez (Santiago, Ed. Abeledo Perrot).

(2007): "La necesaria reforma del proceso civil chileno: algunos apuntes fundamentales", Revista Iberoamericana de Derecho Procesal, Año VI, No 10 (Instituto Iberoamericano de Derecho Procesal). 
(2012): "La ejecución provisional de las sentencias en el Proyecto de nuevo CPC", en Aguirrezabal, M. (Editor): "Justicia civil: Perspectivas para una reforma en la legislación chilena" (Santiago, Universidad de los Andes, Cuadernos de Extensión Jurídica, No 23).

(2013): "Oralidad, eficiencia y garantías en la reforma procesal”, en Del Picó, J. (Editor): La Codificación y la recepción legislativa de las demandas sociales. Apreciación crítica de su evolución en los últimos treinta años (Santiago, Ed. Abeledo Perrot).

Pérez-Ragone, A. (2013): "Derecho a la tutela ejecutiva del crédito: entre mitos, temores y realidad", en Aguirrezabal, M. (Editor): "Justicia civil: Perspectivas para una reforma en la legislación chilena” (Santiago, Universidad de los Andes, Cuadernos de Extensión Jurídica, Núm. 23).

(2011): "Principios de la ejecución civil singular", en PeYrano, J.: Principios Procesales: Tomo II (Buenos Aires, Rubinzal-Culzoni Editores). Pereira, R. (2010): El procedimiento monitorio laboral (Santiago, Ed. Abeledo Perrot).

Pérez-Ragone, A.; Silva, O. (2009): "El imperativo de transparencia patrimonial del deudor como requisito funcional para una ejecución civil eficiente", Revista Ius et Praxis, Año 15, oo 2 (Universidad de Talca).

PICÓ, J. (2012): Las garantías constitucionales del proceso (Barcelona, Ed. Bosch). VARGas, M. (2011): "Reflexiones en torno a la figura del oficial de ejecución en el Proyecto de reforma a la Justicia civil chilena”, en LeTURIA, F. (Editor): Justicia civil y comercial: ¿una reforma cercana? (Santiago, Pontificia Universidad Católica de Chile y Universidad Diego Portales).

VV.AA. (2012): Diseño de un modelo de Oficial de ejecución (Santiago, Pontificia Universidad Católica de Valparaíso). Véase en http://rpc.minjusticia.gob. cl/media/2013/04/Estudio-Diseno-de-un-Modelo-Oficial-de-Ejecucion.pdf [Consultado con fecha 5/11/2013].

VV.AA. (2013): Bases para la reforma al sistema de ejecución en el proceso laboral: Informe ejecutivo (Santiago, AGAL-IEJ). 